\title{
BMJ Open Nailfold capillary morphological characteristics of hand-arm vibration syndrome: a cross-sectional study
}

\author{
QingSong Chen, ${ }^{1,2}$ GuiPing Chen, ${ }^{1,2}$ Bin Xiao, ${ }^{1,2}$ HanSheng Lin, ${ }^{1,2}$ HongYing Qu, ${ }^{1,2}$ \\ DanYing Zhang, ${ }^{1,2}$ MaoGong Shi, ${ }^{3}$ Li Lang, ${ }^{1,2}$ Bei Yang, ${ }^{3}$ MaoSheng Yan ${ }^{1,2}$
}

To cite: Chen QS, Chen GP, Xiao B, et al. Nailfold capillary morphological characteristics of hand-arm vibration syndrome: a crosssectional study. BMJ Open 2016:6:e012983.

doi:10.1136/bmjopen-2016012983

- Prepublication history for this paper is available online To view these files please visit the journal online (http://dx.doi.org/10.1136/ bmjopen-2016-012983).

QC and GC authors contributed equally to this work.

Received 8 June 2016 Revised 27 September 2016 Accepted 29 September 2016

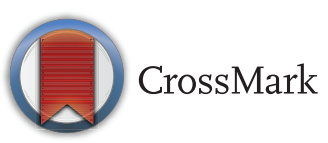

For numbered affiliations see end of article.

Correspondence to Dr Qingsong Chen qschen@gdoh.org

\section{ABSTRACT}

Objective: The purpose of this study was to investigate the characteristics of nailfold capillaroscopy associated with hand-arm vibration syndrome (HAVS).

Methods: In total, 113 male gold miners were recruited: 35 workers who were chronically exposed to vibration and developed vibration-induced white finger were defined as the HAVS group, 39 workers who were exposed to vibration but did not have HAVS were classified as the vibration-exposed controls (VEC) group, and 39 workers without vibration exposure were categorised as the non-VEC (NVEC) group. Video capillaroscopy was used to capture images of the 2nd, 3rd and 4th fingers of both hands. The following nailfold capillary characteristics were included: number of capillaries $/ \mathrm{mm}$, avascular areas, haemorrhages and enlarged capillaries. The experiments were carried out in the same winter. All characteristics were evaluated under blinded conditions.

Results: Significant differences in all morphological characteristics existed between the groups $(p<0.05)$. Avascular areas in the HAVS, VEC and NVEC groups appeared in $74.3 \%, 43.6 \%$ and $25.0 \%$ of participants, respectively. A higher percentage of participants had haemorrhages in the HAVS group (65.7\%) compared with the other groups (VEC: $7.7 \%$ and NVEC: $7.5 \%$ ). The number of capillaries/ $\mathrm{mm}$, input limb width, output limb width, apical width, and ratio of output limb and input limb all had more than $70 \%$ sensitivity or specificity of their cut-off value.

Conclusions: Nailfold capillary characteristics, especially the number of capillaries/mm, avascular areas, haemorrhages, output limb width, input limb width and apical width alterations, revealed significant associations with HAVS.

\section{INTRODUCTION}

Hand-arm vibration syndrome (HAVS) is characterised by asymmetrical vasospasms of the digital arteries. Vibration-induced white finger (VWF), the most dominant symptom and the most typical clinical manifestation of vascular injuries of HAVS, is a secondary form of Raynaud's phenomenon (RP),

\section{Strengths and limitations of this study}

- This is the first study providing several cut-off values of nailfold capillary morphological characteristics to systematically evaluate hand distal vascular alterations resulting from the hand-arm vibration exposure.

- The measurement results in this study are probably representative only for the population in northern areas, as demographic characteristics of populations may vary according to workers' location (eg, tropical areas).

- Further studies targeting tropical workers or a variety of vibrating tools are required in the future.

resulting from enduring occupational exposure to hand-held vibrating tools (eg, drills, buffs and riveters). VWF was first described as an industrial disease in $1985 .^{12}$ Prior to this, HAVS had been recognised legally as an occupational disease since 1957 in China. ${ }^{3}$ The pathogenesis of HAVS is not fully understood, but it is clear that vibration can result in the damage of vascular, neurological and musculoskeletal systems of the upper limbs. ${ }^{45}$ Workers who suffer from HAVS may undergo neurological tingling, numbness in the fingers, sensory perception reductions, tactile discrimination and manipulative dexterity, musculoskeletal swelling, and stiffness in hands or loss of grip strength. HAVS may also result in deterioration of manipulative dexterity ${ }^{6}$ or operation performance impairment.

In this study, we focused on the impact of vibration exposure on arteries. RP has been observed in patients who suffer from enduring exposure to high frequency hand-arm vibration. $^{7-9}$ A positive relationship between high-level hand-arm vibration exposure and the appearance of HAVS vascular symptoms has been reported. ${ }^{10}$ Exposure to highintensity vibration may be related to vascular 
changes in the digits, which include vasospasms, fixed narrowing of the vessel lumen and ischaemia. ${ }^{11}$ The pathophysiology of RP in HAVS is complicated, but it is presumed that chronic vibration exposure may trigger an exaggerated central sympathetic vasoconstrictor reflex and local changes in the digital vessels, vasoactive substances, including endothelin and immunological factors, and alterations in blood viscosity. Furthermore, vascular disorders of HAVS can be observed in at least three ways: digital organic microangiopathy, digital vasospastic phenomenon, and arterial thrombosis in the upper extremities. ${ }^{2} 12$

Nailfold capillaries, which are typically characterised by their hairpin shape, are mostly parallel to the skin surface (figure 1). Their structure can be easily seen in vivo by means of nailfold capillaroscopy. Nailfold capillary abnormalities associated with HAVS can be recognised by structural alterations, such as degeneration of capillary density, avascular areas (figure 2), appearance of enlarged capillaries (figure 3), local haemorrhages (figure 4) and angiogenesis. To assess the condition of capillaries, both morphological characteristic changes and measurements are able to provide disease identification at every stage. The history of capillaroscopy dates back 200 years, and was extensively used after the advent of the work of Maricq and LeRoy. ${ }^{13}$ Cutolo et $a l^{14}$ began their studies on capillaries, eventually detailing a capillaroscopy procedure ${ }^{15}$ and suggesting a set of parameters which should be taken into consideration, including the presence of enlarged and giant capillaries, haemorrhages, loss of capillaries, disorganisation of the vascular array, and ramified/bushy capillaries. These researchers also defined the major sclerodermic nailfold capillaroscopy patterns in the 'early', 'active' and 'late' stages. Despite the general description and measurement of nailfold capillaries, the categorisation of nailfold capillaries is also worthwhile. Sakaguchi et $a l^{16}$ classified workers' nailfold capillary morphology into five types. Based on previous studies, their capillaroscopy

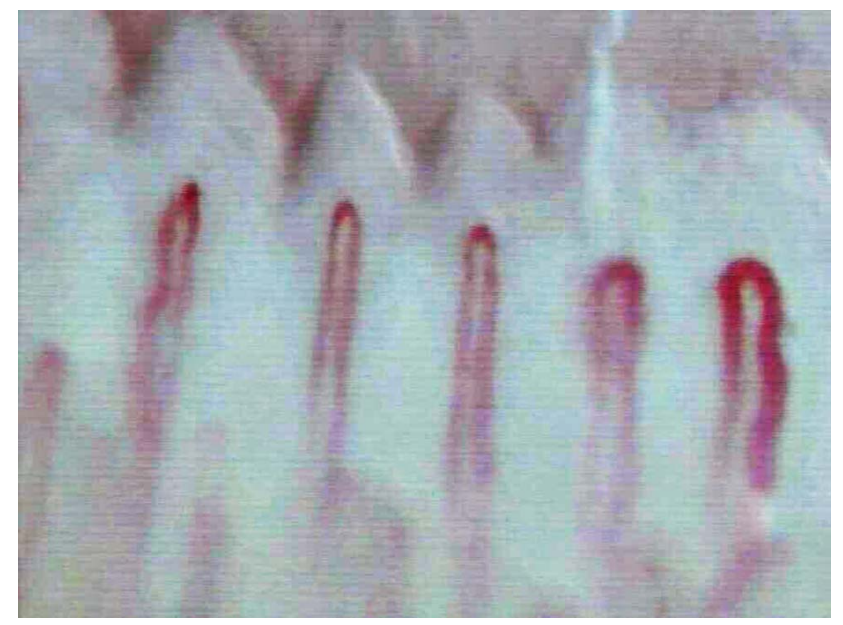

Figure 1 Normal capillaries.

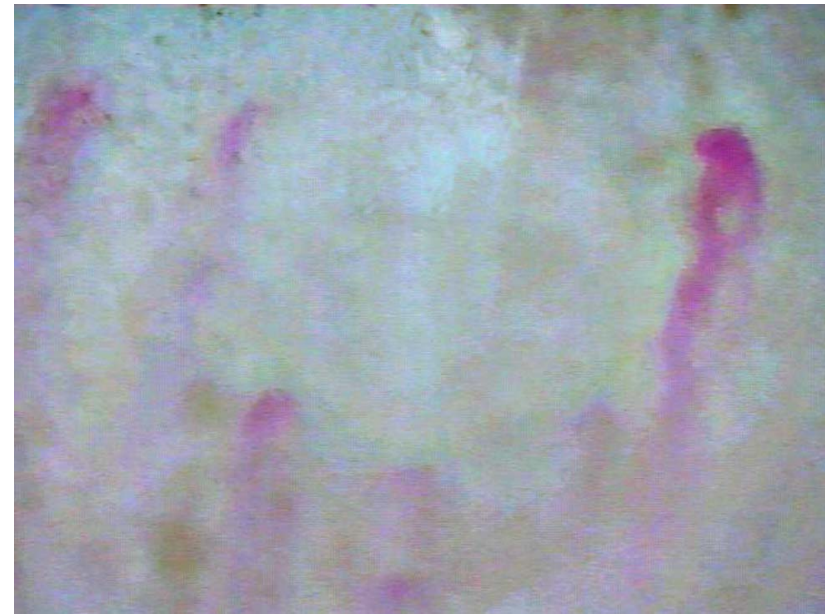

Figure 2 Avascular area.

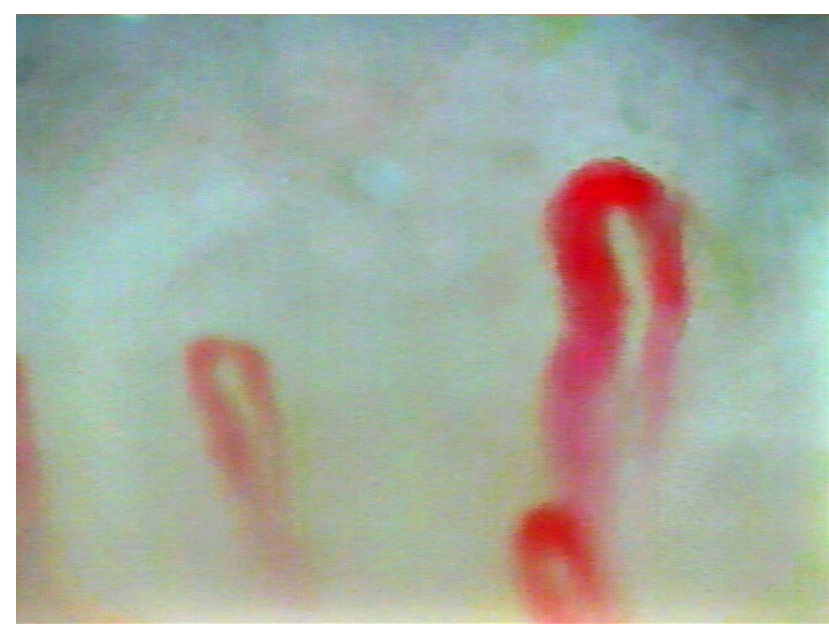

Figure 3 Enlarged capillary.

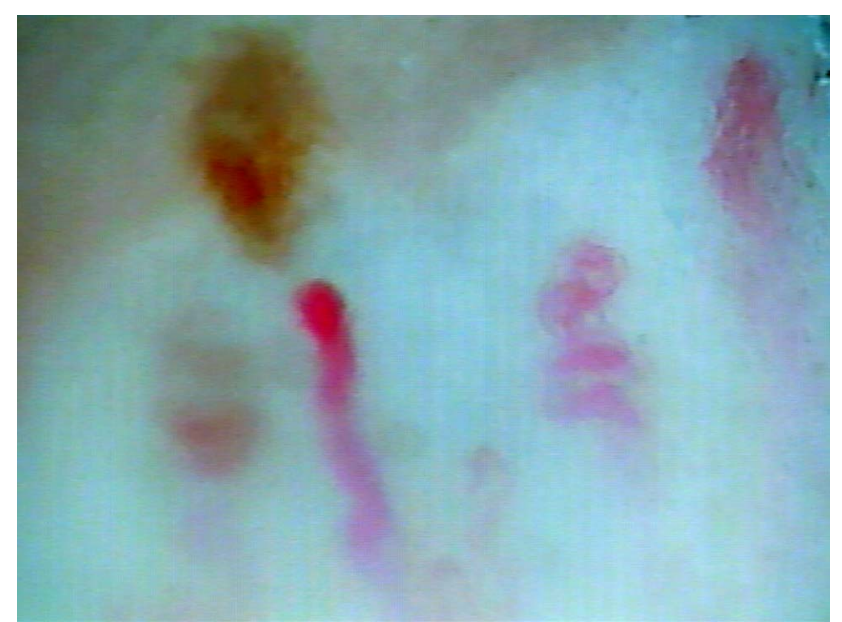

Figure 4 Microhaemorrhage.

studies involved other Raynaud diseases, ${ }^{14} 1517$ such as connective autoimmune rheumatic diseases, ${ }^{18} 19$ systemic lupus erythematosus, ${ }^{20}$ dermatomyositis $^{21}$ and Sjögren syndrome. ${ }^{22}$ This method was later introduced 
in the scanning of VWF. In 2011, Mahbub and Harada ${ }^{23}$ reported that few capillaroscopic studies on VWF existed, and the ones that did commonly focused on capillary abnormalities on limb dropouts and/or morphology alterations. Smith $e t a l^{4}$ standardised the method of interpreting individual capillaries reliably and introduced a more practical way for novices to distinguish normal capillaries and abnormal capillaries individually after a quick training course.

Compared with existing HAVS diagnostic methods, capillaroscopy provides a relatively objective and feasible way to assess HAVS. Vascular Doppler and duplex scanning, cold provocation tests, finger skin temperature (FST), finger systolic blood pressure (FSBP) and plethysmography are extensively applied in HAVS diagnosis. However, some of these methods have been questioned for several reasons. For example, the performance conditions of the cold provocation test are quite unpleasant, which might be unbearable for the participants, and its test outcomes may lead to unreproducible measurement results. ${ }^{25}$ Some studies have indicated that use of FSBP without pre-cold or post-cold stress digit plethysmography or cold provocation might underestimate the severity of a patient's condition. Even though a demonstrable decrease in FSBP occurs on cooling, it is not specific to HAVS, which means other diseases or factors may contribute to the FSBP drop. ${ }^{10}$ The diagnostic ability of FSBP in the assessment of HAVS remains a controversial topic. ${ }^{10} 23 \quad 2627$ Plethysmography requires expensive equipment and it is complicated to perform. ${ }^{23}$ The effectiveness of FST on HAVS diagnosis has been doubted for its accuracy of readings, which heavily depend on the thermistor probe position. The specificity and sensitivity of the results were found not to be consistent and reproducible between studies. ${ }^{25}{ }^{26} \mathrm{VWF}$ is the 'combination of sympathetic hyperactivity and lesion to structures and functions in the walls of blood vessels in the skin, ${ }^{5}$ The capillary alterations reveal the vascular injuries of HAVS. Thus, the morphology of injured vessels can be visually observed through capillaroscopy, which cannot be achieved by using other methods. Capillaroscopy provides an accurate way to measure and analyse data objectively. Also, capillaroscopy has advantages of low cost, non-invasiveness and simple manipulation. ${ }^{28} 29$

Thus, this study aimed to investigate the characteristics of nailfold capillaroscopy associated with HAVS.

\section{METHODS}

\section{Participants}

All participants were male workers exposed to hand-arm vibration for at least 12 continuous months. Participants with any of the following conditions were not recruited in this study: history of current hypertension, diabetes, hepatitis, nephritis, immunological diseases or trauma (muscular, neural and osseous). Those who smoked or had alcohol intake within 24 hours or with fingers affected by recent local trauma were not recruited in the experiment. Participants were recruited by cluster sampling from three Sub gold Companies within one gold industry covering 90 rock drillers in Zhaoyuan district of Shandong province, China. The workers who participated in this study were invited to participate in a health examination. A cold provocation test was performed on all participants after nailfold capillaroscopy examination.

In total, 113 participants were recruited and participated in this study: 35 patients, defined by the revealed VWF symptoms after the cold provocation test, as well as the workers' personal description of VWF history with evidence (photo or third party witnesses), were categorised as the HAVS group. In addition, 39 age-matched participants, occupying the same hand-arm vibration exposed position but without symptoms of HAVS, were categorised as the vibration-exposed controls (VEC) group. Finally, 39 age-matched participants who were employed in positions without hand-arm vibration exposure were classified as the non-VEC (NVEC) group.

Gold miner information was obtained by a face-to-face interview. The questionnaire, based on the questionnaire by SWS, included four parts: basic personal information, employment status, habits, and medical history and clinical characteristics. Basic personal information included name, nationality, age, height, weight, degree of education and dominant hand. Employment status covered a detailed history of past and current work ability, job titles, types of applied vibrating tool exposure, and duration of vibration exposure. Habits consisted of smoking, alcohol intake and daily transportation. Medical histories and clinical characteristics were documented in detail, and included hypertension, diabetes, immunological diseases, hepatitis, nephritis, primary Raynaud's diseases, medicine intake and digit alteration (appearance of VWF or cyanosis, tingling, numbness, etc).

Informed consent was obtained from each respondent.

\section{Vibration measurement}

Vibration produced by rock drill operation was measured with a VI-400 Pro 3-axial human vibration monitor (QUEST Technologies, Oconomowoc, Wisconsin, USA) by a qualified technician. Daily 8 hours' time-weighted average vibration exposure level (A (8)) was calculated according to ISO 5439-2:2001. Total hand-transmitted vibration exposure dose was calculated as Cumulative Exposure Index (CEI) under the following formula:

Where $t_{d i}$ is the working days per year of each tool, $t_{y i}$ is the years of using vibrating machine. Napierian logarithm CEI $(\mathrm{LN}(C E I))$ was used as a final index to calculate the vibration exposure dose.

\section{Nailfold capillaroscopy}

Vibration exposure should have occurred at least 24 hours prior to the nailfold capillaroscopy examination. At the beginning of the examination procedure, all participants adapted to room temperature $\left(20-22^{\circ} \mathrm{C}\right)$ with their hands placed on the table at heart level for at 
least $10 \mathrm{~min}$. Meanwhile, FST measurements of the second knuckle of each finger were also taken. The experiments were all carried out in the same winter.

Nailfold capillaroscopy was performed by capillaroscopy (CSW-XW2000 video-capillaroscopy, Shenzhen, Guangdong Province, China), which was equipped with a $\times 400$ optical probe, on the second, third and fourth fingers of both hands which are prone to developing representative morphological patterns, including enlarged capillaries, capillary density, angiogenesis, local haemorrhages and avascular areas. A drop of immersion oil was applied to the nailfold bed in order to increase the translucency of the keratin layer. Images of capillaries in the middle areas of the nailfold within $2 \mathrm{~mm}$ were captured for a continuous 4 pictures per digit, 24 pictures per participant. Capillaroscopy was performed by a trained technician.

For every image, the following parameters were taken into analysis: the number of capillaries $/ \mathrm{mm}$, avascular areas, haemorrhages, enlarged capillaries, input limb width, output limb width, apical width, capillary limbs length, capillary total width, and ratio of output limb and input limb. Only the distal row of capillaries was used for imagery and data counting. Capillaries with a limb larger than $20 \mu \mathrm{m}$ were defined as 'enlarged capillaries', and the lack of at least two successive capillaries was defined as an avascular area. ${ }^{30}$ All characteristics were evaluated under blinded conditions.

The measurements of input limb width, output limb width, apical width, capillary limbs length and capillary total width were calculated by Adobe Photoshop CS6 (Adobe Systems, San Jose, California, USA). Before calculation, the images were modified: the edges were sharpened, and brightness and contrast were adjusted properly.

\section{Statistical analysis}

The measurement results (the number of capillaries/ $\mathrm{mm}$, input limb width, output limb width, apical width, capillary limbs length and capillary total width) are expressed as mean \pm SD (with $95 \%$ CI); categorical information (avascular areas, haemorrhages and enlarged capillaries) is presented as individual cohorts (with percentage). The Kolmogorov-Smirnov test was used to evaluate the normal distribution of the measurement results; a Student's t-test or one-way analysis of variance (ANOVA) was used to analyse the normally distributed quantitative values, and the Mann-Whitney $U$ test was used to analyse the non-normally distributed ones. The $\chi^{2}$ test was used to analyse categorical information. The measurement results were also evaluated via sensitivity analysis, and then the optimal specificity and sensitivity were selected as cut-off points determined by the Youden index for each variable for discriminating between the HAVS group and NVEC group. Logistic regression was applied to observe the association of habits and nailfold capillary characteristics. A probability value of $\mathrm{p}<0.05$ (two-sided) was considered statistically significant. All analyses were performed using SPSS, V.19.0 (SPSS, Chicago, Illinois, USA).

\section{RESULTS}

\section{Demographic characteristics of participants}

In total, 113 male gold miners were recruited in this study. As shown in table 1, the average ages of the HAVS, VEC and NVEC groups were 42.8, 40.72 and 41.37 years, respectively. The HAVS group had longer seniority than the VEC group; the average seniority of the HAVS and VEC groups was 127.60 and 70.77 months, respectively. The body mass indexes of the HAVS group $(22.52 \mathrm{~kg} /$ $\left.\mathrm{m}^{2}\right)$, VEC group $\left(23.92 \mathrm{~kg} / \mathrm{m}^{2}\right)$ and NVEC group $\left(24.59 \mathrm{~kg} / \mathrm{m}^{2}\right)$ were slightly different. Approximately $80 \%$ of participants were smokers and more than $50 \%$ of participants drank alcohol. The LNCEI of the HAVS group was 10.52 , which is marginally higher than that of the VEC group at 9.91 .

\section{Results of nailfold capillary characteristics}

Nailfold capillary characteristics in this study are shown in table 1. Haemorrhages existed to a greater extent in the HAVS group $(65.7 \%)$ compared with the VEC and NVEC groups $(7.7 \%$ and $7.5 \%$, respectively). Enlarged capillaries were also observed more frequently in the HAVS group $(60.0 \%)$ compared with the VEC $(25.6 \%)$ and NVEC (25.0\%) groups. Avascular areas were evident in $74.3 \%$ of HAVS participants, but these areas were only apparent in $43.6 \%$ and $25.0 \%$ of participants in the VEC and NVEC groups, respectively.

The results of the sensitivity analysis are presented in table 2. The average number of capillaries $/ \mathrm{mm}$ in the HAVS group was $7.41 \pm 1.79$ limbs, compared with 8.87 \pm 1.80 limbs in the VEC group and $9.69 \pm 1.22$ limbs in the NVEC group; the cut-off value was 8.75 capillaries/ $\mathrm{mm}$ with a sensitivity of $76.9 \%$ and a specificity of $77.1 \%$, while the area under the receiver operating characteristic (ROC) curve was 0.846 with a $95 \%$ CI ranging from 0.753 to 0.939 . The average output limb width $(\mu \mathrm{m})$ in the HAVS group was $21.09 \pm 4.44$ compared with $16.06 \pm 2.05$ and $15.74 \pm 2.21$ in the VEC and NVEC groups, respectively. The cut-off value of this characteristic was 16.72 , with $80.0 \%$ sensitivity and $74.4 \%$ specificity; the area under the ROC curve was 0.866 and the $95 \%$ CI ranged from 0.781 to 0.950 . Input limb width $(\mu \mathrm{m})$ had an average of $15.77 \pm 3.26$ in the HAVS group compared with $13.05 \pm 1.75$ and $12.84 \pm 1.60$ in the VEC and NVEC groups, respectively. The cut-off value was 13.73, with similar sensitivity $(77.1 \%)$ and specificity $(74.7 \%)$, and the area under the ROC curve was 0.782 with a $95 \%$ CI ranging from 0.669 to 0.895 . The mean values of apical width $(\mu \mathrm{m})$ were $21.40 \pm 4.34,16.65 \pm 3.41$ and $16.92 \pm 2.53$ in the HAVS, VEC and NVEC groups, respectively. The cut-off value of this parameter was 18.51, with a sensitivity of $80.0 \%$ and a specificity of $79.5 \%$; the area under the ROC curve was 0.823 with a $95 \%$ CI ranging from 0.714 to 0.932 . The average of 
Table 1 Demographic characteristics and nailfold capillary characteristics of participants

\begin{tabular}{|c|c|c|c|c|}
\hline & HAVS (n=35) & VEC $(n=39)$ & NVEC (n=39) & p Value \\
\hline \multicolumn{5}{|l|}{ Demographic characteristics } \\
\hline Age (years), mean $\pm S D$ & $42.80 \pm 5.96$ & $40.72 \pm 7.35$ & $41.37 \pm 8.74$ & $>0.05$ \\
\hline Seniority (months), mean $\pm S D$ & $127.60 \pm 63.68^{*}$ & $70.77 \pm 50.27$ & - & $<0.001 \dagger$ \\
\hline $\mathrm{BMI}$, mean $\pm \mathrm{SD}$ & $22.52 \pm 2.59^{\star}, \ddagger$ & $23.92 \pm 2.75$ & $24.59 \pm 3.18$ & 0.008 \\
\hline Smoking, $\mathrm{n}(\%)$ & $28(80)$ & $34(87.2)$ & $33(82.5)$ & $>0.05$ \\
\hline Alcohol drinking, n (\%) & $19(54.3)$ & $21(53.8)$ & 29 (72.5) & $>0.05$ \\
\hline $\mathrm{LNCEI}$, mean $\pm \mathrm{SD}$ & $10.52 \pm 1.07$ & $9.91 \pm 1.12$ & - & $<0.05 \dagger$ \\
\hline \multicolumn{5}{|l|}{ Nailfold capillary characteristics } \\
\hline Haemorrhages, n (\%) & $23(65.7)^{\star}, \ddagger$ & $3(7.7)$ & $3(7.5)$ & $<0.001$ \\
\hline Enlarged capillaries, $\mathrm{n}(\%)$ & $21(60.0) \ddagger$ & $9.98(25.6) \S$ & $9.75(25.0)$ & 0.04 \\
\hline Avascular areas, $\mathrm{n}(\%)$ & $26(74.3) \ddagger$ & $17(43.6) \S$ & $10(25.0)$ & $<0.001$ \\
\hline Number of capillaries/mm, mean \pm SD & $7.41 \pm 1.79^{\star}, \ddagger$ & $8.87 \pm 1.80 \S$ & $9.69 \pm 1.22$ & $<0.001$ \\
\hline Output limb width $(\mu \mathrm{m})$, mean $\pm S D$ & $21.09 \pm 4.44^{*}, \ddagger$ & $16.06 \pm 2.05$ & $15.74 \pm 2.21$ & $<0.001$ \\
\hline Input limb width $(\mu \mathrm{m})$, mean $\pm S D$ & $15.77 \pm 3.26^{\star}, \ddagger$ & $13.05 \pm 1.75$ & $12.84 \pm 1.60$ & $<0.001$ \\
\hline Apical width $(\mu \mathrm{m})$, mean $\pm S D$ & $21.40 \pm 4.34^{*}, \ddagger$ & $16.65 \pm 3.41$ & $16.92 \pm 2.53$ & $<0.001$ \\
\hline Capillary limbs length $(\mu \mathrm{m})$, mean $\pm S D$ & $191.77 \pm 52.88^{\star}, \ddagger$ & $180.21 \pm 64.99$ & $159.83 \pm 29.40$ & $<0.05$ \\
\hline Capillary total width $(\mu \mathrm{m})$, mean $\pm S D$ & $50.71 \pm 10.92 \ddagger$ & $42.33 \pm 6.25$ & $43.16 \pm 5.32$ & 0.001 \\
\hline Ratio of output limb and input limb $(\mu \mathrm{m})$, mean \pm SD & $1.36 \pm 0.13^{\star}, \ddagger$ & $1.25 \pm 0.08$ & $1.24 \pm 0.10$ & $<0.001$ \\
\hline \multicolumn{5}{|c|}{$\begin{array}{l}\text { Napierian logarithm } C E I(L N(C E I)) \text { was used as a final index to calculate the vibration exposure dose. } \\
\text { *HAVS versus VEC: } p<0.05 \text {. } \\
\text { †Comparison between HAVS versus VEC. } \\
\text { †HAVS versus NVEC: } p<0.05 \text {. } \\
\text { §VEC versus NVEC: } p<0.05 \text {. } \\
\text { BMI, body mass index; CEI, Cumulative Exposure Index; HAVS, hand-arm vibration syndrome; NVEC, non-vibration-exposed controls; VEC, } \\
\text { vibration-exposed controls. }\end{array}$} \\
\hline
\end{tabular}

capillary limb lengths $(\mu \mathrm{m})$ was $191.77 \pm 52.88$ in the HAVS group compared with $180.21 \pm 64.99$ and $159.83 \pm 29.40$ in the VEC and NVEC groups, respectively. The cut-off value of capillary limb length was 165.37 , while the sensitivity $(65.7 \%)$ and specificity $(56.4 \%)$ were relatively lower than the other characteristics. The trend in the capillary total widths $(\mu \mathrm{m})$ was similar to that of the capillary limb length, while the averages of the HAVS, VEC and NVEC groups were $50.71 \pm 10.92,42.33 \pm 6.25$ and $43.16 \pm 5.32$, respectively; the cut-off value was 44.46 with a low sensitivity (62.9\%) and specificity (53.8\%). The mean values of the output and input limb ratio were $1.36 \pm 0.13,1.25 \pm 0.08$ and $1.24 \pm 0.10$ in the HAVS, VEC and NVEC groups, respectively. The cut-off value was 1.29 with a sensitivity of $74.0 \%$ and specificity of $71.8 \%$; the area under the ROC curve was 0.775 , and the $95 \%$ CI ranged from 0.669 to 0.881 .
It can be seen that the characteristics of output limb width, input limb width and apical width had quite good sensitivity $(80.0 \%, 77.1 \%$ and $80.0 \%)$, while the number of capillaries $/ \mathrm{mm}$ and apical width had the greatest specificity. Apical width was graded the best sensitivity $(80.0 \%)$ and specificity (79.5) at the same time among the four characteristics. Thus, number of capillaries/ $\mathrm{mm}$, output limb width, input limb width and apical width are considered to be the optimum parameters to the HAVS diagnosis. Significant differences in all nailfold capillary characteristics existed between all groups $(\mathrm{p}<0.05)$.

\section{Results of association of nailfold capillaroscopy} with habits

Of the 74 participants in the HAVS and NVEC groups who had a nailfold capillaroscopy, there was an even

Table 2 Sensitivity analysis of various nailfold capillary parameters

\begin{tabular}{lcllll}
\hline & $\begin{array}{l}\text { Cut-off } \\
\text { value }\end{array}$ & $\begin{array}{l}\text { Sensitivity } \\
(\%)\end{array}$ & $\begin{array}{l}\text { Specificity } \\
(\%)\end{array}$ & $\begin{array}{l}\text { Area under the } \\
\text { ROC curve }\end{array}$ & \begin{tabular}{l} 
95\% Cl \\
\hline Number of capillaries/mm
\end{tabular} \\
Output limb width, $\mu \mathrm{m}$ & 8.75 & 76.9 & 77.1 & 0.846 & 0.753 to 0.939 \\
Input limb width, $\mu \mathrm{m}$ & 16.72 & 80.0 & 74.4 & 0.866 & 0.781 to 0.950 \\
Apical width, $\mu \mathrm{m}$ & 13.73 & 77.1 & 74.7 & 0.782 & 0.669 to 0.895 \\
Capillary limb length, $\mu \mathrm{m}$ & 18.51 & 80.0 & 79.5 & 0.823 & 0.714 to 0.932 \\
Capillary total width, $\mu \mathrm{m}$ & 165.37 & 65.7 & 56.4 & 0.686 & 0.561 to 0.812 \\
Ratio of output limb and input limb & 44.46 & 62.9 & 53.8 & 0.704 & 0.580 to 0.829 \\
ROC, receiver operating characteristic. & 1.29 & 74.0 & 71.8 & 0.775 & 0.669 to 0.881 \\
\hline
\end{tabular}


Table 3 Distribution of smoking and alcohol intake in the HAVS and NVEC groups

\begin{tabular}{llll}
\hline & $\begin{array}{l}\text { HAVS } \\
(\mathbf{n}=\mathbf{3 5})\end{array}$ & $\begin{array}{l}\text { NVEC } \\
(\mathbf{n}=39)\end{array}$ & $\mathbf{p ~ V a l u e ~}$ \\
\hline Smoking, $\mathrm{n}(\%)$ & $28(80.0)$ & $34(87.2)$ & 0.403 \\
Alcohol drinking, $\mathrm{n}(\%)$ & $19(54.3)$ & $21(53.8)$ & 0.970 \\
\hline \multicolumn{4}{l}{ HAVS, hand-arm vibration syndrome; NVEC, non-vibration-exposed } \\
controls.
\end{tabular}

distribution $(p>0.05)$ of participants who smoke or drank alcohol (table 3). In total, $80 \%$ and $87.2 \%$ of participants in the HAVS and NVEC groups were smokers and $54.3 \%$ and $53.8 \%$ of participants drank alcohol.

\section{Results of logistic regression results}

For both habits (smoking and alcohol drinking), univariate analysis of individual habits did not yield any association with nailfold capillary characteristics $(p>0.05)$. Some studies have revealed that there is a relationship between vessel wall injuries and alcohol intake, which may contribute to the development of enlarged capillaries; however, no significant differences between these two factors were observed in our study; thus, no further multivariable analysis was performed (table 4).

\section{Results of bivariate correlations}

We assumed that the capillary characteristics (number of capillaries $/ \mathrm{mm}$, haemorrhages, enlarged capillary and avascular areas) might be correlated with each other and with the symptoms of VWF. Therefore, we explored the bivariate correlations of the variables mentioned above (table 5).

Haemorrhages, enlarged capillaries and avascular areas positively correlated with VWF $(r=0.607, p<0.001 ; r=0.348$, $\mathrm{p}<0.05$; and $\mathrm{r}=0.486, \mathrm{p}<0.001$, respectively), while the number of capillaries $/ \mathrm{mm}(\mathrm{r}=-0.601, \mathrm{p}<0.001)$ negatively correlated with VWF. Avascular areas negatively correlated with the number of capillaries $/ \mathrm{mm} \quad(\mathrm{r}=-0.568, \mathrm{p}<0.001)$ and positively correlated with haemorrhages $(\mathrm{r}=0.416$, $\mathrm{p}<0.001)$. Haemorrhages negatively correlated with the number of capillaries $/ \mathrm{mm}(\mathrm{r}=-0.458, \mathrm{p}<0.001)$. Avascular areas did not correlate with enlarged capillaries, and enlarged capillaries did not correlate either with the number of capillaries/mm or haemorrhages.

\section{DISCUSSION}

Nailfold capillaroscopy examination has been applied for RP for years. The observed abnormal specific vascular patterns are distinctive from one pathological stage to another. Therefore, this method should include a number of parameters, and the proper value range of each parameter needs to be set up in order to provide a more complete assessment.

HAVS is a secondary form of RP. Although some studies have explored nailfold capillaroscopy in persons with HAVS, its parameters were either not comprehensive or were mainly focused on the classification of variables for levels of disease categorisation. Few studies suggested parameters for clinical cut-off values, and most of the nailfold capillaroscopy studies focused on the semiquantitative scale methods of nailfold capillary patterns, rather than giving exact values of nailfold capillary measurements. The capillary alterations in immunological diseases with respect to RP are quite apparent, and they contrast in every pathological stage. However, the situation is different in people with HAVS, and the prevention of HAVS development needs reference values as thresholds for judging vibration exposure to workers. This will ultimately help to decide if a worker is still suitable for his/her position.

In this study, we attempted to obtain a set of reliable reference values of vascular measurements, and also to find out the relationship between each vascular pattern and VWF pathological changes.

As the bivariate correlation analysis results showed, the appearance of haemorrhages negatively correlated

Table 4 Logistic regression results of several nailfold capillary characteristics associated with the habits of smoking and alcohol intake in the HAVS and NVEC groups

\begin{tabular}{|c|c|c|c|c|}
\hline Control factor(s) & $N(n=74)$ & Wald & p Value & OR $(95 \% \mathrm{Cl})$ \\
\hline \multicolumn{5}{|c|}{ Haemorrhages, n (\%) } \\
\hline Smoking & $62(83.8)$ & 0.286 & $>0.05$ & 1.412 (0.398 to 5.007$)$ \\
\hline Alcohol drinking & $40(54.1)$ & 0.232 & $>0.05$ & 0.789 (0.301 to 2.071$)$ \\
\hline \multicolumn{5}{|c|}{ Enlarged capillaries, $n(\%)$} \\
\hline Smoking & $62(83.8)$ & 1.485 & $>0.05$ & 2.192 (0.621 to 7.740$)$ \\
\hline Alcohol drinking & $40(54.1)$ & 0.629 & $>0.05$ & 1.462 (0.572 to 3.739$)$ \\
\hline \multicolumn{5}{|c|}{ Avascular areas, $n(\%)$} \\
\hline Smoking & $62(83.8)$ & 0.017 & $>0.05$ & $1.085(0.313$ to 3.755$)$ \\
\hline Alcohol drinking & $40(54.1)$ & 0.522 & $>0.05$ & $0.713(0.284$ to 1.787$)$ \\
\hline \multicolumn{5}{|l|}{ VWF, n (\%) } \\
\hline Smoking & $62(83.8)$ & 0.693 & $>0.05$ & 1.703 (0.486 to 5.960$)$ \\
\hline Alcohol drinking & $40(54.1)$ & 0.005 & $>0.05$ & 0.968 (0.386 to 2.432$)$ \\
\hline
\end{tabular}


Table 5 Bivariate correlation of several nailfold capillaroscopy characteristics between the HAVS and NVEC groups

\begin{tabular}{|c|c|c|c|c|c|}
\hline & $\begin{array}{l}\text { Number of } \\
\text { capillaries/mm }\end{array}$ & Haemorrhages & $\begin{array}{l}\text { Enlarged } \\
\text { capillaries }\end{array}$ & $\begin{array}{l}\text { Avascular } \\
\text { areas }\end{array}$ & VWF \\
\hline Number of capillaries/mm & 1 & $r=-0.458^{\star *}$ & $r=-0.157$ & $r=-0.568^{* *}$ & $r=-0.601^{* *}$ \\
\hline Haemorrhages & - & 1 & $r=0.178$ & $r=0.416^{\star \star}$ & $r=0.607^{\star *}$ \\
\hline Enlarged capillaries & - & - & 1 & $r=-0.004$ & $r=0.348^{*}$ \\
\hline Avascular areas & - & - & - & 1 & $r=0.486^{\star \star}$ \\
\hline VWF & - & - & - & - & 1 \\
\hline
\end{tabular}

with the number of capillaries/mm, which meant that the more haemorrhages that were observed, the less capillaries were present within $1 \mathrm{~mm}$. The measurement number of capillaries $/ \mathrm{mm}(\mathrm{r}=-0.568, \mathrm{p}<0.001)$ and haemorrhages $(\mathrm{r}=0.416, \mathrm{p}<0.001)$, correlated, negatively and positively correlated with avascular areas, which indicated that the avascular areas arose with the appearance of haemorrhages and the degeneration of capillary number. The manifestation of VWF positively correlated with haemorrhages $(r=0.607, p<0.001)$, enlarged capillaries $(0.348, \mathrm{p}<0.05)$ and avascular areas $(\mathrm{r}=0.486$, $\mathrm{p}<0.001$ ), but negatively correlated with the number of capillaries $/ \mathrm{mm}(\mathrm{r}=-0.601, \mathrm{p}<0.001)$. This revealed that more haemorrhages, enlarged capillaries and avascular areas associated with more severe VWF (and vice versa). In addition, fewer capillaries appearing within $1 \mathrm{~mm}$ associated with more serious VWF.

Thus, we infer that operating hand-held vibrating tools, to a certain degree, might lead to neurological and vascular damage of the hands, characterised by vasoconstriction caused by endothelium damage, followed by morphological alterations of the capillaries. Pathological changes of capillary alterations manifest as enlarged or tortuous capillaries occurring as blood hypoxia, which arise from vascular compensation. Moreover, as a consequence of chronic vessel wall impairment and rupture, erythrocytes are able to cross over the vessel wall and then form haemorrhages, which give rise to degeneration of capillaries. Finally, capillaries begin to drop off, which causes avascular areas.

Shandong province, located in the northeast of China, has extreme cold weather in the winter. Gold miners who are exposed to hand-arm vibration under such weather and working conditions may develop capillary impairment, characterised as VWF, which is seen as vasoconstriction.

Morphological alterations can be observed on nailfold capillaroscopy. A previous study indicated that haemorrhages are the bridge between enlarged capillaries and avascular areas. ${ }^{18}$ Our study agrees with this, as, in the HAVS group, the ratio of haemorrhages was similar to that of enlarged capillaries, while avascular areas increased up to $74.3 \%$. We suggest that the appearance of enlarged capillaries and haemorrhages triggered vascular degeneration, forming the avascular areas. Thus, the proportions of haemorrhages and enlarged capillaries were greater than the presence of avascular areas. However, it is possible that since many of the participants with HAVS were still undergoing the process of developing HAVS, the existence of enlarged capillaries and haemorrhages but not avascular areas could be observed. In the VEC and NVEC groups, the avascular areas were greater than or equal to the existence of haemorrhages and enlarged capillaries, which were in accordance with our hypothesis.

Participants with HAVS had more haemorrhages and enlarged capillaries than those in the VEC and NVEC groups. Generally, enlarged capillaries are much more likely to be observed than haemorrhages in participants who are chronically exposed to hand-arm vibration, and those participants tend to develop HAVS. Once participants are exposed to hand-arm vibration for a certain duration, for example, those in the HAVS group, haemorrhages are more likely to be observed. We propose that haemorrhages form after enlarged capillaries appear, as previous studies have mentioned. Thus, it is feasible that haemorrhages and enlarged capillaries should be included as reference characteristics.

Avascular areas most likely related to capillary density $(\mathrm{r}=-0.568, \mathrm{p}<0.001)$. The inhomogeneous distribution of capillaries results in a drop-off, which decreases the amount of capillaries, creating avascular areas.

The effectiveness in counting the number of capillaries per millimetre in this study is consistent with previous studies of patients with systemic scleroderma and healthy participants. ${ }^{31} 32$ Ingegnoli $e t$ al indicated that the number of capillaries per millimetre in healthy participants ranged from 7 to 10 . Our results, $7.41 \pm 1.79 / \mathrm{mm}$ in the HAVS group, $8.87 \pm 1.80 / \mathrm{mm}$ in the VEC group, and $9.69 \pm 1.22 / \mathrm{mm}$ in the NVEC group, are consistent with the previous data, and we also believe that counting the number of capillaries per millimetre is a proper way to judge capillary abnormalities. The results of number of capillaries per millimetre published here have a reference significance for HAVS, with a cut-off value of 8.75 capillaries within $1 \mathrm{~mm}$, of which sensitivity and specificity are $76.9 \%$ and $77.1 \%$, respectively.

In the process of setting reliable parameters of HAVS reference values, the sensitivity analysis in our study showed several parameters with considerable sensitivity 
or specificity. Parameters with considerable sensitivity (more than 77\%) were output limb width, input limb width and apical width, while the parameters with considerable specificity were number of capillaries $/ \mathrm{mm}$ and apical width. It is worth mentioning that apical width shares a considerable sensitivity and a considerable specificity. Here, we recommend that the parameters of number of capillaries/mm, output limb width, input limb width and apical width can be taken into consideration as HAVS examination parameters, especially the apical width. What makes the sensitivity and specificity of these parameters so different is the limb shape itself. Generally, the output or input limb is uneven, which means that the measurement point varies, thus resulting in diverse measurements. However, the capillary apex is fixed in a narrow range; thus, the measurement of apical width would be relatively more objective than measurement of the limbs.

The results of this study are generally in accordance with previous RP studies. We believe it is because HAVS is a secondary form of RP that shares a familiar pathology with other Raynaud diseases. ${ }^{14} 33$ Therefore, we suppose our results are reliable in the assessment of HAVS.

There are some limitations in this study. Demographic characteristics of populations may vary according to workers' location in China. As an example, the participants in this study were from northern China, who adapted to the extreme cold winters, while the population in tropical China, have a relatively poor adaption cold temperature; this will lead to different vascular measurement results. Hence, the measurement results in this study are probably representative only for the population in northern areas, and further studies are required for the tropical populations. Nevertheless, in future studies, we highly recommend that a weighted index be considered as one of the assessment rules, which may enhance the nailfold capillaroscopy analysis with more accuracy, and also raise the HAVS assessment procedure efficiency.

\section{Author affiliations \\ ${ }^{1}$ Guangdong Province Hospital for Occupational Disease Prevention and Treatment, Guangzhou, Guangdong, China \\ ${ }^{2}$ Guangdong Provincial Key Laboratory of Occupational Disease Prevention and Treatment, Guangzhou, Guangdong, China \\ ${ }^{3}$ Yantaishan Hospital, Yantai, Shandong, China}

Contributors $Q C$ and GC conceived of the study and were responsible for the design and search strategy. GC, DZ and BY were responsible for conducting the search. MY and GC conducted the data analysis and interpretation. The initial draft of the manuscript was prepared by QC and GC. All authors provided input to the analysis plans, interpretation of data and critical revision of the successive drafts of the manuscript.

Funding This study was funded by the National Science Foundation of China (NSFC; grant number 81202183); and by the Science and Technology Program of Guangdong, China (STPG; grant number 2013B051000065); and by the Open Projects Program of Guangdong Provincial Key Laboratory of Occupational Disease Prevention and Treatment (grant number 2012A061400007-03).
Competing interests None declared.

\section{Patient consent Obtained.}

Ethics approval This study was approved by the Ethical Committee of Guangdong Province Hospital for Occupational Disease Prevention and Treatment.

Provenance and peer review Not commissioned; externally peer reviewed.

Data sharing statement Additional data are available by emailing the corresponding author at qschen@gdoh.org

Open Access This is an Open Access article distributed in accordance with the Creative Commons Attribution Non Commercial (CC BY-NC 4.0) license, which permits others to distribute, remix, adapt, build upon this work noncommercially, and license their derivative works on different terms, provided the original work is properly cited and the use is non-commercial. See: http:// creativecommons.org/licenses/by-nc/4.0/

\section{REFERENCES}

1. Cutolo M, Pizzorni C, Secchi ME, et al. Capillaroscopy. Best Pract Res Clin Rheumatol 2008;22:1093-108.

2. Noel B. Pathophysiology and classification of the vibration white finger. J Peripher Nerv Sys 2000;5:242.

3. Lin W, Chunzhi Z, Qiang Z, et al. The study on hand-arm vibration syndrome in China. Ind Health 2005;43:480-3.

4. Griffin MJ. Handbook of human vibration. Academic press, 2012.

5. Gemne G. Diagnostics of hand-arm system disorders in workers who use vibrating tools. Occup Environ Med 1997;54:90-5.

6. Sauni R, Toivio P, Pääkkönen R, et al. Work disability after diagnosis of hand-arm vibration syndrome. Int Arch Occup Environ Health 2015;88:1061-8.

7. Nyantumbu B, Barber CM, Ross $M$, et al. Hand-arm vibration syndrome in South African gold miners. Occup Med (Lond) 2007:57:25-9.

8. Harada N, Mahbub MH. Diagnosis of vascular injuries caused by hand-transmitted vibration. Int Arch Occup Environ Health 2008;81:507-18.

9. Hatron PY, Frimat P, Hachulla E. [Raynaud's phenomena of occupational origin]. Rev Prat 1998;48:1653-8.

10. Heaver $\mathrm{C}$, Goonetilleke KS, Ferguson $\mathrm{H}$, et al. Hand-arm vibration syndrome: a common occupational hazard in industrialized countries. J Hand Surg Eur Vol 2011;36:354-63.

11. Maundrell A, Proudman SM. Epidemiology of Raynaud's phenomenon. In: Wigley FM, Herrick AL, Flavahan NA, eds. Raynaud's phenomenon. Springer, 2015:21-35.

12. Olsen N. Centrally and locally mediated vasomotor activities in Raynaud's phenomenon. Scand J Work Environ Health 1987:13:309-12.

13. Maricq HR, LeRoy EC. Patterns of finger capillary abnormalities in connective tissue disease by "wide-field" microscopy. Arthritis Rheum 1973;16:619-28.

14. Cutolo M, Grassi W, Matucci Cerinic M. Raynaud's phenomenon and the role of capillaroscopy. Arthritis Rheum 2003;48:3023-30.

15. Cortes S, Cutolo M. Capillarosecopic patterns in rheumatic diseases. Acta Reumatol Port 2006;32:29-36.

16. Sakaguchi S, Miyai N, Takemura S, et al. Morphologic classification of nailfold capillary microscopy in workers exposed to hand-arm vibration. Ind Health 2011;49:614-18.

17. Smith V, De Keyser F, Pizzorni C, et al. Nailfold capillaroscopy for day-to-day clinical use: construction of a simple scoring modality as a clinical prognostic index for digital trophic lesions. Ann Rheum Dis 2010;70:180-3.

18. Cutolo M, Sulli A, Secchi ME, et al. The contribution of capillaroscopy to the differential diagnosis of connective autoimmune diseases. Best Pract Res Clin Rheumatol 2007;21:1093-108.

19. Cutolo M, Sulli A, Secchi ME, et al. Nailfold capillaroscopy is useful for the diagnosis and follow-up of autoimmune rheumatic diseases. A future tool for the analysis of microvascular heart involvement? Rheumatology (Oxford) 2006:45 (Suppl 4):iv43-6.

20. Bongard $\mathrm{O}$, Bounameaux $\mathrm{H}$, Miescher PA, et al. Association of anticardiolipin antibodies and abnormal nailfold capillaroscopy in patients with systemic lupus erythematosus. Lupus 1995;4:142-4.

21. Marie I, Hachulla E, Hatron PY, et al. Polymyositis and dermatomyositis: short term and longterm outcome, and predictive factors of prognosis. J Rheumatol 2001;28:2230-7. 
22. Tektonidou M, Kaskani E, Skopouli FN, et al. Microvascular abnormalities in Sjögren's syndrome: nailfold capillaroscopy. Rheumatology (Oxford) 1999;38:826-30.

23. Mahbub M, Harada N. Review of different quantification methods for the diagnosis of digital vascular abnormalities in hand-arm vibration syndrome. $J$ Occup Health 2011;53: 241-9.

24. Smith V, Beeckman S, Herrick AL, et al., EULAR study group on microcirculation. An EULAR study group pilot study on reliability of simple capillaroscopic definitions to describe capillary morphology in rheumatic diseases. Rheumatology (Oxford) 2016;55:883-90.

25. Harada N. Cold-stress tests involving finger skin temperature measurement for evaluation of vascular disorders in hand-arm vibration syndrome: review of the literature. Int Arch Occup Environ Health 2002;75:14-19.

26. Poole K, Elms J, Mason HJ. The diagnostic value of finger systolic blood pressure and cold-provocation testing for the vascular component of hand-arm vibration syndrome in health surveillance. Occup Med (Lond) 2004;54:520-7.
27. Thompson A, House R, Manno M. The sensitivity and specificity of thermometry and plethysmography in the assessment of hand-arm vibration syndrome. Occup Med (Lond) 2008;58:181-6.

28. Etehad Tavakol M, Fatemi A, Karbalaie A, et al. Nailfold capillaroscopy in rheumatic diseases: which parameters should be evaluated? Biomed Res Int 2015;2015:974530.

29. Filosa G, De Angelis R. European Handbook of Dermatological Treatments. Springer Berlin Heidelberg. Capillaroscopy 2015:1107-14.

30. Ingegnoli F, Gualtierotti R, Lubatti C, et al. Feasibility of different capillaroscopic measures for identifying nailfold microvascular alterations. Semin Arthritis Rheum 2009;38:289-95.

31. Ingegnoli $F$, Gualtierotti $\mathrm{R}$, Lubatti $\mathrm{C}$, et al. Nailfold capillary patterns in healthy participants: a real issue in capillaroscopy. Microvasc Res 2013;90:90-5.

32. Hoerth C, Kundi M, Katzenschlager R, et al. Qualitative and quantitative assessment of nailfold capillaries by capillaroscopy in healthy volunteers. Vasa 2012;41:19-26.

33. Herrick AL. Pathogenesis of Raynaud's phenomenon. Rheumatology (Oxford) 2005;44:587-96. 